[0212-7199 (2007) 24: 6; pp 300-304] ANALES DE MEDICINA INTERNA Copyright (C) 2007 ARAN EDICIONES, S.L.

AN. MED. INTERNA (Madrid) Vol. 24, N. ${ }^{\circ}$ 6, pp. 300-304, 2007

\title{
Machado, Moix y Montalbán: tres vidas cegadas por el humo
}

\section{J. MONTES SANTIAGO}

Servicio de Medicina Interna. Complejo Hospitalario Universitario Meixoeiro. Vigo, Pontevedra

\author{
MACHADO, MOIX AND MONTALBÁN: SMOKE GETS IN YOUR \\ LIVES
}

\begin{abstract}
RESUMEN
Antonio Machado (enfermedad pulmonar crónica), Terenci Moix (enfisema) y Manuel Vázquez Montalbán (infarto agudo de miocardio) murieron de las complicaciones derivadas de su inveterado hábito tabáquico. Todos ellos fueron conscientes de los perjuicios que les ocasionaba tal adicción y en algún momento intentaron abandonarla. Los testimonios de sus contemporáneos o sus mismos escritos ofrecen en ocasiones dramáticas muestras de esta lucha. Sin embargo, recayeron en la misma y ello les ocasionó una muerte prematura antes de cumplir los 65 años. Con la panorámica de 60 años que separan a los dos últimos escritores del primero, se ofrece una sumaria perspectiva histórica sobre la adquisición de los conocimientos científicos en este periodo de tiempo que han propiciado un cambio de actitud hacia el tabaco.
\end{abstract}

PALABRAS CLAVE: Antonio Machado. Terenci Moix. Vázquez Montalbán. Muerte por tabaco.

\begin{abstract}
The writers Antonio Machado (pulmonary chronic disease), Terenci Moix (emphysema) and Manuel Vázquez. Montalbán (acute myocardial infarction) died of the complications derived from their inveterate habitforming tobacco. They were aware of the prejudices that a such addiction was causing and tried, in some moment, to leave it. In addition, the testimonies of their contemporary or their same writings offered dramatic samples of this struggle. Nevertheless, they relapsed and tobacco caused them a premature death before 65 years. With a panoramic of 60 years among the last two authors and Machado, a brief historical perspective is offered on the acquisition of scientific knowledge that changed the attitudes towards tobacco during this period of time.
\end{abstract}

KEY WORDS: Antonio Machado. Terenci Moix. Vázquez Montalbán. Tabacco-related death.

Montes Santiago J. Machado, Moix y Montalbán: tres vidas cegadas por el humo. An Med Interna (Madrid) 2007; 24: 300 -304.

\section{INTRODUCCIÓN}

En las acaloradas controversias que se suscitaron antes y después de la aprobación de la Ley de Regulación del Tabaco a finales del 2005, un argumento sutil deslizado por algunos intelectuales sobre las "bondades" del tabaco consistió en decir que, por la costumbre, este era un ingrediente fundamental en su proceso creativo. Una excusa perfecta. Algo parecido a “ ¿Cómo iba a escribir una sola página sin mis aliados, los cigarrillos?". Pero precisamente esa pregunta la formuló textualmente Terenci Moix en una memorable reflexión titulada Yo fui esclavo del tabaco, escrita tres años antes de su muerte, justo tras serle diagnosticado un enfisema pulmonar. Y prosi- gue: "Pero los Ducados no me han convertido en Joyce. ¿Cómo hacer el amor sin aspirar, después, una calada, como hacían las heroínas de la nouvelle vague? Pero no se me presentó la oportunidad, porque gracias al tabaquismo entré directamente en la impotencia sexual" (1). En este artículo se repasan las circunstancias vitales de tres escritores que murieron antes de los 65 años de edad por problemas directamente relacionados con su hábito tabáquico. La separación de más de 60 años -Vázquez Montalbán nace el mismo año de la muerte de Machado y Terenci Moix 4 años despuéspermite cierta perspectiva histórica sobre los conocimientos acumulados que han permitido un cambio en la actitud hacia tal hábito. 


\section{SEMBLANZA DE TRES AUTORES}

\section{ANTONIO MACHADO}

Nació en 1875 en Sevilla en una familia de larga tradición liberal pues su padre fue amigo de Giner de los Ríos, el fundador de la Institución Libre de Enseñanza y su abuelo, médico y profesor de Ciencias Naturales, ardiente defensor de la I República. En 1883 la familia se traslada a Madrid, al ser nombrado el abuelo profesor de la Universidad Central. Allí Antonio estudiará en la Institución Libre de Enseñanza. En 1893 su padre, autor de numerosos estudios sobre el folklore andaluz y gallego, morirá de tuberculosis, dejando a la familia en delicada situación económica. En 1899, Antonio viaja a París, junto con su hermano mayor Manuel y allí conoce a escritores como Oscar Wilde y Pío Baroja y queda deslumbrado por la poesía simbolista de Verlaine. Ello motivará que a su regreso a España empiece a publicar sus primeros poemas. En un segundo viaje en 1902 coincide con Rubén Darío. Al volver a Madrid conoce a Juan Ramón Jiménez y publica Soledades. En 1907 se traslada a Soria como catedrático de francés. Allí se casa con Leonor Izquierdo que cuenta a la sazón 15 años y él 35. Publica entonces Soledades, galerías y otros poemas. En 1911 con una Beca viaja a París donde asiste a las Clases del filósofo Henry Bergson. Entonces Leonor enferma de tuberculosis lo que motiva su regreso precipitado a Soria. Un año después morirá sumiendo a Antonio en la desesperación que motivará su traslado a Baeza (Jaén) donde se dedica a la reflexión y enseñanza. En 1912 aparece Campos de Castilla que le consagra como poeta. En 1917 conoce a Federico García Lorca y en 1919 se traslada a Segovia. En 1924 edita Nuevas Canciones, y entre 1926 y 1932 escribe piezas teatrales con su hermano Manuel, de las cuales la de mayor éxito es La Lola se va a los Puertos. En 1928 conoce a la poetisa Pilar de Valderrama, a quien llamará Guiomar, con la que mantendrá una relación sentimental hasta el estallido de la Guerra Civil. Se implica en la defensa del advenimiento de la República, colaborando con personalidades como Marañón, Ortega y Gasset y Ramón Pérez de Ayala. En 1931 se traslada a Madrid donde enseñará en los Institutos Calderón de la Barca y Cervantes. Escribe textos en prosa bajo los seudónimos de Juan de Mairena y Abel Martín. Debido a la Guerrra Civil marcha a Valencia, donde en 1937 publica su último libro La guerra, con dibujos de su hermano José. En 1939 parte al exilio hacia Francia donde morirá $(2,3)$.

\section{TERENCI MOIX}

Nació en Barcelona en 1943. Su verdadero nombre era Ramón Moix i Messeguer pero pronto adoptó el seudónimo más conocido en homenaje al poeta latino Terencio. Tras residir en París y Londres y desempeñar gran variedad de oficios, publica sucesivamente en catalán La torre de los Vicios Capitales (1968), Olas sobre una roca desierta (1969, premio Josep Pla de novela) y El día que va morir Marilyn (1969, Premio Crítica Serra d'Or) que le consagran como un autor literario iconoclasta, vindicador de la cultura de los 60 e icono de la cultura gay. Autor muy polifacético con incursiones en el teatro donde escribió tanto obras como adaptaciones (fue famosa por ejemplo su adaptación del Hamlet shakesperiano). Posteriormente comienza a escribir con el Antiguo Egipto como protagonista fundamental. Con 22 viajes a dicho país y sus cenizas esparcidas a su muerte en el Valle de los Reyes publicará con esta temática algunas de sus obras más conocidas: Terenci del Nilo (1971) El sueño de Alejandría (1989), No digas que fue un sueño (1986, Premio Planeta) o El Arpista ciego (2002, Premio Lara de novela). Su figura fue muy popular por la sempiterna sonrisa, los ojos chispeantes, su naturaleza extrovertida y también por la aguda sátira del llamado mundo del corazón en obras como Chulas y famosas o por su peculiar manera de conducir el programa de entrevistas televisivas Más estrellas que en el cielo. Una faceta que le granjeó también gran aceptación fueron sus escritos sobre personajes cinematográficos plasmados en los sucesivos volúmenes Mis inmortales del cine, en los que estuvo trabajando hasta su muerte. Además de los tres volúmenes de memorias con el título general de El peso de la paja es preciso también resaltar su prolífica faceta como articulista en diarios como TeleExprés, El Correo Catalán, Nuevos Fotogramas, El País o El Mundo. Murió en el año 2003 en Barcelona a los 61 años (4).

\section{MANUEL VÁZQUEZ MONTALBÁN}

Nació en Barcelona en 1939. Licenciado en Filosofía y Letras y en Periodismo, pronto empezó a colaborar en prensa y en la década de los 60 se dio a conocer como poeta al ser elegido para la Antología de Josep María Castellet Nueve novísimos poetas españoles. Autor muy prolífico, con más de 100 libros e innumerables artículos periodísticos, prólogos y otras colaboraciones literarias, en 1985 se le concedió el Premio Nacional de las Letras Españolas por el conjunto de su obra. Fue encarcelado por su oposición al régimen franquista y con diversas vicisitudes, siempre estuvo vinculado al Partido Comunista Español. Comenzó a ser conocido por sus colaboraciones en la revista Triunfo, casi siembre bajo seudónimo, con aceradas críticas a la sociedad franquista, y que más tarde se recogerían en los libros Crónica sentimental de España o Escritos subnormales. Esta faceta periodística la mantuvo hasta su muerte siendo colaborador habitual tanto en diarios y revistas nacionales (La Vanguardia, Avui, El País, Por favor, Hermano Lobo, Interviu) como internacionales (La Reppublica, Il Manifesto, Le Monde diplomatique). En 1990 publicó Galíndez (novela sobre el asesinato en Nueva York del exiliado vasco Jesús de Galíndez, ordenado por el dictador dominicano Trujillo) por la que obtuvo el Premio Nacional de Literatura en 1991. Recibió también multitud de premios (Planeta, el internacional de Literatura Policiaca en Francia, el Premio de la Crítica, etc). Su faceta más conocida es la de novelista entre las que destaca las pertenecientes a la extensa saga del detective Pepe Carvalho, con títulos como: Yo maté a Kennedy (1972), Los pájaros de Bangkok (1982), Asesinato en el Comité Central (1981), El balneario (1986), El delantero centro fue asesinado al atardecer (1988), El laberinto griego (1991) o Milenio (2003), su obra póstuma. Tal saga dará lugar a versiones televisivas y cinematográficas. Otras recordadas novelas son El pianista (1985), Los alegres muchachos de Atzavara (1987), El estrangulador (1994) o Erec y Enide (2002). Cultivó la crónica política nacional -"Yo soy un cronista" le dirá a Terenci Moix, en una entrevista televisiva- en libros como Pasionaria y los siete enanitos (1995), Un polaco en la corte del rey Juan Carlos (1996) o La aznaridad (2003) y también internacional con Y Dios entró en la Habana (1998) 
o Marcos, el señor de los espejos (1999) (sobre el líder zapatista mexicano). Siempre siguió cultivando la poesía que fue recogida en la antología Memoria y deseo, obra poética (1963-1990). También es imprescindible mencionar su entusiasmo como gourmet y crítico gastronómico, plasmado en múltiples artículos y libros y frecuentemente presente en sus novelas. Murió en octubre del 2003 a los 64 años (5).

\section{Antonio Machado: apurando un vaso de negro humo}

Antonio Machado murió de tristeza. Frecuentemente lo repiten sus biografías (2,3). La inquebrantable fidelidad a la causa republicana que motivó un largo periplo por España y el exilio final en Francia; la separación a causa de la guerra de Guiomar, su gran amor otoñal; el distanciamiento afectivo e ideológico de su hermano Manuel, que ahora militaba en el bando franquista; las inquietudes por la salud de su anciana madre que manifestaba signos de demencia senil; la pérdida en la frontera francesa de la maleta con sus últimas pertenencias... todo ello va a contribuir a acelerar la muerte del autor de Campos de Castilla. Esta ocurrirá a los 64 años. Sin embargo, apenas se resalta la enfermedad pulmonar crónica del poeta producida por su tenaz hábito tabáquico. No obstante, esta actuará como un enemigo interior, carcomiendo los muros del castillo interior del escritor, que se vendrá definitivamente abajo ante las hostiles circunstancias externas. Parafraseando, pues, el verso referido a la muerte de su alter ego Abel Martín -llevará a su boca el limpio vaso de pura sombra lleno-, Machado apurará un vaso de negro humo, que también causará su muerte.

Aunque su padre y su mujer murieron de tuberculosis, Machado no parece haberla contraído. Sin embargo, además de adicto al café (consumía cerca de 6 ó 7 tazas diarias) era un recalcitrante fumador, de lo cual abundan los testimonios, tanto escritos como gráficos. Ya Rubén Darío, su amigo y benefactor -que le prestará dinero cuando Machado regrese de París a Soria con Leonor enferma de tuberculosis-, comentará este pertinaz hábito. También los alumnos en los diversos institutos donde enseñó le evocarán con su aspecto desaliñado y en la mano el inevitable cigarrillo. Incluso en el Instituto Cervantes de Madrid le adjudicarán el mote de "La Cenicienta", al traer sus trajes siempre llenos de ceniza e impartir sus clases fumando un pitillo tras otro. Su hermano José referirá igualmente que, en las largas veladas entre los dos hermanos Antonio y Manuel para escribir las obras teatrales, se fumaba con profusión. En las fotografías conservadas de Antonio no es infrecuente sorprenderle cigarrillo en mano. En épocas de penuria apurará hasta la saciedad sus propios cigarrillos y cuando estos escaseaban llegará a probar hierbas aromáticas como sucedáneo. Antonio Machado era consciente de los perjuicios que le ocasionaba tal hábito, aunque no pudo abandonarlo. El Dr. Puche, que le atendió en 1938 en Barcelona, comentaría que llegó a un acuerdo con el escritor para que este pudiera a veces saltarse sus prescripciones. Fácil es imaginar que estas transgresiones tenían que ver, nuevamente, con el tabaco. Por eso, en tales tiempos difíciles, uno de los regalos mejor bienvenidos serán los apreciados cigarrillos, como los que le envía el famoso general Líster. Hacia el final de sus días también agradecerá los que les suministra Juliette Figuères, su vecina en Collioure.

En los testimonios fotográficos conservados de Machado se hace muy patente su progresiva decrepitud (3). Desde la conocida fotografía del Café de Las Salesas en Madrid en 1934 en la que el escritor todavía luce abundante papada, hasta las tomadas en Valencia en 1937 ha pasado un mundo. Él mismo se reconoce viejo y enfermo en una carta escrita a mediados de ese año. Pero las fotografías son mucho más expresivas. En ellas la cara del escritor aparece famélica con profundas arrugas en la frente y hundidos los ojos. Recuerda la facies característica de los pacientes con enfisema pulmonar avanzado. En la última conservada, realizada en la frontera de Francia, al parecer por el escritor Corpus Barga, la cara de Machado, macilento y con una barba de varios días, parece la de un cadáver. Machado está muy debilitado y los testimonios de sus compañeros de exilio refieren su dificultad respiratoria y su "asma" de varios años de evolución. De hecho, José Machado atribuirá la enfermedad final al "enfriamiento" adquirido mientras hacían largas colas y dormían en un vagón abandonado en la estación de Cerbère. Esto acaecía un mes antes de llegar a Collioure. Aquí, Machado, muy postrado, saldrá apenas del pequeño hotel donde se aloja. Atendido por su hermano José y su cuñada, Antonio yacerá junto al lecho de su anciana madre de 85 años, de la que le separa un simple biombo. El médico francés Dr. Cazaben le administra algunas medicinas, probablemente algún balsámico o expectorante como el yoduro potásico o quizá belladona, que eran de los escasos recursos terapéuticos entonces disponibles (6). Sin embargo, comunica a sus familiares que Antonio está desahuciado. Efectivamente, una nueva neumonía o bronquitis, complicada esta vez con una gastroenteritis, produce el decisivo empeoramiento. Durante 4 días Machado está disneico, inquieto, delirando y con gran opresión en el corazón. Dos días antes de su muerte, en una leve mejoría, dicta una carta a un amigo, al fin de la cual estampa una temblorosa firma. Muy poco después entra en coma y muere a las tres y media de la tarde del 22 de febrero de 1939. Su madre le seguirá tres días después a la tumba. Era Miércoles de Ceniza.

\section{Tabaco y salud: disipando históricamente los humos}

Machado acabará pagando los efectos del tabaco en forma de un enfisema o enfermedad pulmonar obstructiva crónica evolucionada. Sin embargo, conviene señalar que en aquellos tiempos sus efectos perjudiciales eran apenas intuidos y todavía no tenía el estigma de tóxico que tendrá después. El primer trabajo que relaciona el hábito tabáquico con una prematura mortalidad no lo publica Richmond Pearl hasta el año en 1938. Y a principios del siglo XX sólo había registrados en la literatura 300 casos de cáncer de pulmón, el tipo de tumor con una relación mas consistentemente probada con el tabaco (7). Incluso, todavía en los años 50, los médicos aparecen en prestigiosas revistas médicas, como JAMA, Lancet o British Medical Journal anunciando las supuestas utilidades terapéuticas del tabaco en ciertas afecciones (8). En la Guerra Española y en la inminente Segunda Guerra Mundial el paquete de cigarrillos se considerará componente primordial en el equipamiento de los soldados. E incluso el asunto del tabaco será empleado con fines proselitistas. Así, la propaganda nazi llegará a contraponer la continencia de dirigentes como Hitler, Mussolini o Franco a la adicción de Churchill, Roosevelt o Stalin (9). Y está por llegar aún el gran momento estelar del tabaco, encarnado en el glamour de las grandes estrellas fumadoras de Hollywood. 
En aquella época el asma, la bronquitis crónica, el enfisema y otros procesos crónicos pulmonares no presentaban límites claramente definidos $(6,7)$. Desde la muerte de Machado todavía pasará más de una década -principios de los años 50para que Bradford Hill y, sobre todo, Peto y Doll inicien en Inglaterra sus pioneros trabajos en médicos británicos. Estos estudios, que fueron corroborados con la publicación de los estudios de cohortes americanas en más de 180.000 varones y refrendados por el famoso Surgeon General's Report Americano sobre Tabaco y Salud de 1964, se han clausurado recientemente de forma definitiva, al cumplirse los 50 años desde su comienzo y tras demostrar de forma incuestionable los efectos deletéreos del tabaco (8-11). En un trabajo similar publicado recientemente en una población noruega seguida durante 25 años, se corrobora de forma definitiva esta mayor mortalidad en fumadores (12). El estudio internacional INTERHEART (13) -que abarcó a cerca de 30.000 hombres en 52 países, la mitad con infarto de miocardio-, ha demostrado de forma incontestable, en coherencia con estudios previos, la relación dosis-efecto entre el consumo de tabaco y el desarrollo de infarto de miocardio. Y recientemente acaba de publicarse el exhaustivo Surgeon General's Report 2006 sobre los incuestionables efectos nocivos sobre los fumadores pasivos (14).

\section{TERENCI MOIX: EL PESO DEL HUMO}

En el caso de Terenci Moix no hacen falta los testimonios ajenos -que los hay y abundantes, tanto gráficos como literarios- porque él mismo relata su experiencia con el tabaco en el artículo citado Yo fui esclavo del tabaco publicado en $\mathrm{El}$ País en junio de 2000 y reeditado con ocasión de su muerte (1). Posteriormente publicó en El Mundo una serie de artículos con el subtítulo de "Fumando muero". Siempre reconoció en los cigarrillos -Celtas y Ducados- a sus asesinos, pero ni aún así consiguió desenredarse de su trampa mortal. Por tanto el título de sus memorias -El peso de la paja- bien podrían convertirse en "El peso del humo", para resaltar esta relación amor-odio entre escritor y tabaco.

Según relató en ese artículo y en otras ocasiones, Terenci, que era adicto al tabaco negro desde los 16 años y que fumaba tres cajetillas al día, intentó desprenderse de su adicción de los modos más diversos: libros de autoayuda, acupuntura, ondas electromagnéticas, parches de nicotina, pastillas, boquillas..., aunque reconocía haber fallado en lo más primordial y se reconocía perteneciente a la "raza de fumadores que quieren dejarlo...sin quererlo dejar". A pesar de haberlo abandonado fugazmente y declararse orgulloso de ello -Me siento muy contento de mí mismo, pero al mismo tiempo me tengo por estúpido por no haberlo dejado antes- volvió a recaer. El desarrollo de un enfisema pulmonar, complicado además con una osteoporosis y fractura vertebral, fruto de los repetidos ciclos de corticoides, motivó diversas hospitalizaciones. También es de justicia advertir que, en consonancia con su talante, declaró que jamás pensaba prohibir que se fumara en su presencia. Dos meses antes de su muerte volvió a ser ingresado en la Clínica Teknon de Barcelona de donde marchó lanzando un dramático grito de iQuiero vivir! De allí salió 15 días antes de su muerte para una hospitalización domiciliaria. Sin embargo, según diversos testimonios, era frecuente verlo desconectar el dispositivo de oxígeno domiciliario para fumar un cigarrillo. El desenlace final se produjo en la madrugada del 2 de abril de 2003. En su ataúd, como un homenaje y quizá también como un recordatorio, alguien colocó un paquete de Ducados.

\section{MANUEL VÁQUEZ MONTALBÁN: LA MUERTE GRIS ESPERA EN BANGKOK}

Un año y medio antes de su muerte y dirigiéndose a los asistentes de un Congreso sobre Cardiopatía isquémica celebrado en Bilbao, Vázquez Montalbán decía: "Les insto a sorprenderme. A que cualquier día de estos descubran cómo resucitar mi ventrículo muerto o cómo compartir la condición de cardiópata con la de aficionado al bacalao al pil-pil" (15). Lamentablemente, como es conocido, esto no fue posible y mientras esperaba su embarque en el aeropuerto de Bangkok el 18 de octubre de 2003, su corazón -esta víscera tan improbable, como le gustaba repetir- sufrió un infarto de miocardio que le ocasionó una muerte súbita. En muchos aspectos parecido a su amigo Terenci, -su prolífica actividad literaria y periodística, su activa militancia izquierdista...-también se le asemejó en este asunto (16). Tras ser intervenido en 1994 para la colocación de un triple bypass coronario, -en cuya convalecencia no dejó de entregar a la prensa sus artículos, ya escritos con antelación, pues era un metódico e infatigable trabajador, dejó de fumar y cuidó su dieta. Diabético, con el característico y entrañable perfil formado por sus ojos vivos tras las sempiternas gafas, con la prematura calva, el intermitente y personal bigote y la abultada cintura, parece un arquetipo del síndrome metabólico. Desgraciadamente, tras su intervención coronaria volvió a fumar y dejarse llevar por sus entusiasmos gastronómicos, por otra parte su gran pasión. La escritora Maruja Torres, gran amiga suya y también de Terenci Moix, comentaría en un artículo de homenaje tras su muerte "que la parte buena (para ambos) es que por fin Terenci va a tener cerca a alguien que le enseñará a comer bien mientras hablan de cine" (17).

\section{EPÍLOGO}

Cada año el tabaco mata a cerca de 5 millones de personas en el mundo y 55.000 en España. Además es el causante principal de los años potenciales de vida perdidos y de los años vividos con discapacidad, es decir la muerte y enfermedad en edades prematuras, en las cuales las personas se encuentran en periodos altamente creativos $(18,19)$. Los tres escritores considerados constituyen un prototipo de este aserto pues ninguno alcanzó los 65 años y en los casos de Terenci Moix y Vázquez Montalbán estaban plenamente inmersos en empresas literarias que quedaron inconclusas o fueron publicadas póstumamente. 


\section{Bibliografía}

1. Terenci Moix. Yo fui esclavo del tabaco. Diario El País. Sección Cultura, 3/04/2003.

2. Gibson I. Ligero de equipaje. La vida de Antonio Machado. Madrid: Santillana (Aguilar), 2006.

3. Serrano Segura JA. (2000-2005). La obra poética de Antonio Machado (consultado 15-07-2006): Disponible en: http://jaserrano.com/Machado.

4. Anónimo. Muere Terenci Moix. Diario La Vanguardia (Barcelona), 3/04/2003 (consultado 25-07-06): Disponible en http://www.xtec.es/ jducros/Terenci\%20Moix.html.

5. Saval JV. Manuel Vázquez Montalbán. El triunfo de un luchador incansable. Madrid: Editorial Síntesis; 2004, 239 pp.

6. Sauret Valet J. EPOC: un viaje a través del tiempo. Barcelona: Healthnet SL. (Rubes Editorial SL), 2000.

7. Morera J. EPOC: aspectos históricos. Algunas pinceladas (consultado: 10-07-2006): Disponible en http://www.asmayepoc.com/html/epoc/historia/perspect $1 . h t m l$.

8. Buschbaum RB, Buschbaum JC. El tabaquismo como factor de riesgo cardiovascular. En: Foody, J, ed. Cardiología Contemporánea: Cardiología preventiva. Barcelona: J \& C Ediciones Médicas, 2002, pp. 177-91.

9. Maldonado-Fernández M. Historia del tabaco. De panacea a epidemia. Med Clin (Barc). 2005; 125: 745-7.

10. Haustein K-O. Tobacco or health?. Berlin: Springer, 2003, 446 pp.

11. Doll R, Peto R, Boreham J, Sutherland I. Mortality in relation to smoking: 50 years' observations on male British doctors. BJM. 2004; 328: 1519-28.
12. Vollset SM, Tverdal A, Gjessing HK. Smoking and deaths between 40 and 70 years of age in women and men. Ann Intern Med. 2006; 144: 381-9.

13. Yusuf S, Hawken S, Ounpuu S et al., Interheart Study Investigators. Effect of potentially modifiable risk factors associated with myocardial infarction in 52 countries (The Interheart Study): Case-control study. Lancet. 2004; 364: 937-52.

14. US Department of Health and Human Services. The health consequences of involuntary exposure to tobacco smoke: A report of Surgeon General. Atlanta Ga: US Department of Health and Human Services, Center for Disease Control and Prevention, Coordinating Center for Health Prevention, National Center for Chronic Disease Prevention and Health Promotion, Office on Smoking and Health, 2006; 727 pp. (Consultado 30-07-2006): Disponible en http://www.cdc.gov/tobacco.

15. Vázquez Montalbán M. El corazón como fruto amargo o cazador solitario. Rev Esp Cardiol 2002, 56: 169-72.

16. Vázquez Montalbán M. Ni siquiera se llamaba Terenci. Diario El País, 3/04/03.

17. Torres M. Es mentira. Diario El País, 20/10/2003. (Consultado el 25-072006): Disponible en http://www.vespito.net/mvm/adios18.html.

18. World Health Organization. The World Health Report 2001. Geneva: WHO; 2001.

19. Ezzati M, López AD. Estimates of global mortality attributable to smoking in 2000. Lancet 2003; 362: 847-52. 